\title{
High stream intermittency in an alpine fluvial network: Val Roseg, Switzerland
}

\author{
Amael Paillex $\mathbb{D}^{1 *}{ }^{1 *}$ Andre R. Siebers $\mathbb{D}^{1},{ }^{1}$ Christian Ebi, ${ }^{2}$ Jorrit Mesman, ${ }^{3}$ Christopher T. Robinson ${ }^{1,4}$ \\ ${ }^{1}$ Department of Aquatic Ecology, Eawag, Swiss Federal Institute of Aquatic Sciences and Technology, Dübendorf, Switzerland \\ ${ }^{2}$ Department of Urban Water Management, Eawag, Dübendorf, Switzerland \\ ${ }^{3}$ Department F. A. Forel for Environmental and Aquatic Sciences, University of Geneva, Geneva, Switzerland \\ ${ }^{4}$ Institute of Integrative Biology, ETH Zürich, Zürich, Switzerland
}

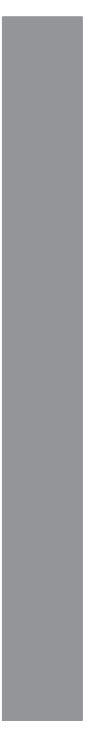

\begin{abstract}
More than one-third of the world's rivers cease to flow and go dry on a periodic basis-so-called intermittent rivers. The frequency and duration of flow intermittency in running waters are increasing due to climate change and water demands for human use. Intermittency effects on stream biodiversity and ecosystem functioning are dramatic and are expected to become increasingly prevalent in alpine landscapes in the near future. This project used modified field sensors to measure flow intermittency, temperature, and water origin (groundwater, precipitation, glacier) at high spatio-temporal resolution throughout an alpine fluvial network (Val Roseg, Switzerland). We continuously recorded water presence in 30 tributary streams and validated sensor performance with fieldcollected measures. Three different flow regimes were observed in the network, including periodically intermittent, seasonally intermittent, and permanently flowing streams. Twenty-four streams ( $80 \%$ of recorded streams) dried at least once during the sampling period. Principal components analysis along with generalized additive models showed alpine streams with low average temperature and high conductivity (groundwater-fed) were prone to permanent flow, whereas streams with higher average temperature and low conductivity (glacier-fed) typically had intermittent flow. The field sensors proved precise for simultaneously measuring flow intermittency, temperature, and water origin at high resolution throughout the river network. Overall, this approach provides an effective way to develop eco-hydrological models that examine the effects of flow intermittency on biodiversity and ecosystem functioning in riverine networks.
\end{abstract}

Natural intermittent rivers and ephemeral streams (IRES) periodically experience cessation of surface flow (Datry et al. 2017). Intermittent and ephemeral waters make up at least $30 \%$ of the world's fluvial systems (Datry et al. 2014), and it is likely that an even higher proportion of low-order streams and headwaters have intermittent surface flow at the global scale (Meyer et al. 2007; Snelder et al. 2013). In this context, flow regimes today are shifting from perennial to intermittent around the globe in response to changes in land use and climate (Leigh et al. 2016). Despite a substantial increase in the number of studies of IRES since the 1990s, major research gaps still exist in understanding how variation in flow cessation affects running waters (Leigh et al. 2016; Stubbington et al. 2018). Part of the complexity in advancing the science of IRES is due to the difficulty of capturing high spatial and temporal resolution data at fine scales of surface flow cessation

*Correspondence: amael.paillex@hispeed.ch

Additional Supporting Information may be found in the online version of this article.
(Costigan et al. 2017; Stubbington et al. 2018). Indeed, IRES are known to exhibit wide variation in the frequency, timing, and duration of surface flow and drying (Costigan et al. 2017). In low-order streams and headwaters, in particular, surface flow can cease and resume at very fine temporal and spatial scales (Gomi et al. 2002). Characterizing this critical aspect of flow variation within IRES, and its drivers, is thus a vital first step toward understanding how riverine biodiversity and ecosystem processes respond to surface flow cessation, particularly in areas prone to environmental change.

Some of the least studied IRES occur in alpine catchments (Robinson et al. 2016). Alpine streams exhibit wide variation in flow regimes driven by high landscape heterogeneity and seasonal variation in contributions from glacial melt, snow melt, groundwater, and precipitation (Malard et al. 1999; Brown et al. 2003; Robinson et al. 2016). Furthermore, extensive landscape gradients, shallow aquifers, and limited transient water storage create the potential for flashy flows and a relatively high proportion of naturally occurring intermittent headwaters (Malard et al. 2000; Robinson and Matthaei 2007; Robinson et al. 2016). Although flow intermittency occurs 
naturally in alpine landscapes, current climate models predict increased temperatures and temporal shifts in precipitation within European alpine regions, with significant increases in intermittency and drying of alpine waters (Horton et al. 2006; Zemp et al. 2006; IPCC 2014). In particular, alpine streams influenced by glacial melt are likely to experience significant changes in temporal patterns of intermittency and consequently ecosystem properties and processes (Milner et al. 2009; Slemmons et al. 2013; Cauvy-Fraunie et al. 2015). Headwater streams contribute greatly to the flow and biodiversity of alpine river networks (Alexander et al. 2007; Meyer et al. 2007), and ongoing glacial recession will significantly impact these systems and consequently influence downstream waters (Brown et al. 2017; Milner et al. 2017). Before we can understand and model the impact of increased flow intermittency on biodiversity and ecosystem function in alpine fluvial networks, we urgently need to accurately characterize the types of flow regime of streams in alpine landscapes.

Typically, gauging stations are used for obtaining surface flow measures of streams and rivers (Snelder et al. 2013; Oueslati et al. 2015; Leigh and Datry 2017). Stations are usually located at single sites on large, permanent rivers and streams (Snelder et al. 2013; Stubbington et al. 2018), thus the upper network of low-order streams that are more likely to be intermittent is largely excluded (Meyer et al. 2007; Snelder et al. 2013). Furthermore, it also can be difficult to assess whether missing gauge data are due to surface-water drying, malfunction and maintenance, or transition to a lentic state (Oueslati et al. 2015; Stubbington et al. 2018). Many other direct measures (field mapping, aerial photos, remote sensing, citizen science; Fritz et al. 2013, Gallart et al. 2016, Robinson et al. 2016, Spence and Mengistu 2016) and indirect indicators of intermittency (temperature, modeling, aquatic community structure; Constantz et al. 2001, Cid et al. 2016, GonzálezFerreras and Barquín 2017) are used, often in combination, to identify the distribution of IRES at finer spatial resolution (see Stubbington et al. 2018). However, these are largely time, labor, and cost-intensive for measuring fine-scale temporal variation in flow intermittency, especially for whole river networks. Modeling can provide accurate flow estimates through interpolation of gauging station data (e.g., Larned et al. 2011), but is highly reliant on the quality and spatial resolution of field data (Bishop et al. 2008; Fritz et al. 2013). As such, highresolution (spatial and temporal) field measurements are still required to fully characterize the flow regime of IRES in river networks.

Technological advances in sensor development have resulted in smaller, less expensive products for high-resolution datalogging of chemical, physical, and hydrological attributes of freshwaters (Porter et al. 2009; Rode et al. 2016). In particular, small, inexpensive electrical resistance (ER) sensors can measure saturated flow conditions from which streamflow timing can be accurately inferred (Blasch et al. 2002; Chapin et al. 2014). In general, ER sensor data allow examination and evaluation of the variation in timing, duration, and frequency of intermittency among streams at high temporal resolution (e.g., Jaeger and Olden 2012; Goulsbra et al. 2014; Peirce and Lindsay 2014). In fact, ER sensors modified from light sensors also have the advantage of simultaneously recording temperature (Adams et al. 2006; Chapin et al. 2014), thus allowing assessment of the interactions between flow and temperature regimes. Importantly, these compact, low cost sensors can be implemented in multiple streams at various locations in riverine networks to capture the full extent of intermittency for better model development of ecosystem properties at the network scale.

In this study, we used ER sensors modified from Hobo light/temperature data-loggers to quantify flow intermittency of tributary streams throughout an alpine catchment at high spatio-temporal resolution. Our objectives were to: (1) accurately measure the presence and absence of surface water at a high frequency (hourly); (2) validate the measured values with field surveys; (3) develop metrics from the data to characterize sites with respect to the degree of flow intermittency; and (4) assess relationships between temperature and flow data from different stream types found in the study.

\section{Materials and methods}

\section{Study catchment}

The Val Roseg is located in the Bernina Massif of the Swiss Alps in southeast Switzerland (Supporting Information Fig. S1). It comprises the $66.5 \mathrm{~km}^{2}$ catchment area of the Roseg River, which flows into the Inn River within the Danube Basin (Burgherr and Ward 2001). Bedrock consists of crystalline gneiss. The highest peak is $4049 \mathrm{~m}$ above sea level (a.s.l.) (Piz Bernina), while the lowest point is $1760 \mathrm{~m}$ a.s.l. Mean annual precipitation is about 1000 mm (last 30 yr) (MeteoSwiss, Piz Corvatsch weather data, 1987-2017). The fluvial network consists of a braided floodplain river with numerous small tributaries. The main channel is strongly influenced by runoff from the Roseg and Tschierva glaciers. Runoff from the Roseg Glacier flows into a proglacial lake at about $2100 \mathrm{~m}$ a.s.l. before flowing downstream from the lake outlet. Both glaciers have strongly receded over the last decades (e.g., Roseg Glacier has receded $4 \mathrm{~km}$ since 1850) (Swiss Glacier Monitoring Network, Tockner et al. 2002; Sertic and Robinson 2015). Several smaller hanging and rock glaciers occur along the catchment and contribute to tributary runoff.

Below the confluence of both glacier streams, the Roseg braids through a 150-500 m wide floodplain before entering a confined valley at $1990 \mathrm{~m}$ a.s.l. (Tockner et al. 2002; Uehlinger et al. 2003). The floodplain itself has a gentle slope with coarse alluvial sediments and sparse vegetation, whereas the steep side-slopes of the floodplain valley are covered with successional vegetation (i.e., grasses, shrubs, trees); current tree line is at about $2300 \mathrm{~m}$ a.s.l. (Malard et al. 2000; Burgherr and Ward 2001). Numerous tributary streams enter the proglacial lake and the main channel network (Robinson et al. 2016), either flowing down the valley side-slopes or originating in 
the floodplain from upwelling groundwater (Supporting Information Fig. S1).

\section{Water sensor development}

HOBO (Onset Computer Corporation, Bourne, MA, U.S.A.) Pendant temperature/light $64 \mathrm{~K}$ data loggers were modified into water sensors to measure electric conductivity between two electrodes (Supporting Information Fig. S2a). The procedure for modifying the loggers was taken from Chapin et al. (2014). External electrodes were installed into predrilled holes on the housing cap, and connected to the light sensor contact pads after removal of the light sensor itself (Chapin et al. 2014). Electrical conductivity (EC) scales strongly with salinity, but the conductivity of water is markedly higher than that of air or dry soil even at low salinity (Chapin et al. 2014). Thus, the presence of water between the electrodes causes a clear increase in EC. Due to the original purpose and programming of the logger, the sensor records and outputs relative conductivity as Lux (light intensity), with a reading linearly correlated with EC up to about $1000 \mu \mathrm{S} \mathrm{cm}^{-1}$ (Chapin et al. 2014). For validation, water sensors were placed first in a dry environment, then inundated in nanopure water (Barnstead, Type D11971) and later in water with a conductivity of $100 \mu \mathrm{S} \mathrm{cm}^{-1}$. The sensors recorded no signal in the dry environment, a weak but distinct signal in the nanopure water (relative conductivity on average $1696 \pm 115 \mathrm{Lux}$ ) and a much stronger signal in the water with conductivity of $100 \mu \mathrm{S} \mathrm{cm}^{-1}$ (relative conductivity on average $66,959 \pm 3906 \mathrm{Lux}$ ). In the field, flow intermittency was inferred from the measure of relative conductivity with all nonzero values interpreted as presence of water, and zero values as absence. To assess potential conductivity differences among sensors, values were spot tested against two campaigns of field measures using a portable conductivity meter (WTW model 3110, Weilheim, Germany) with linear regression.

Each water sensor was attached inside a protective PVC tube (3.5-cm diameter, $12-\mathrm{cm}$ long) using plastic tie-wraps and secured to the stream bottom using metal rods (Supporting Information Fig. S2b,c). The sensors were thus able to record water at $2 \mathrm{~cm}$ depth (Supporting Information Fig. S2b). Each sensor was placed on the riverbed in areas of adequate flow; pool habitats were not used for placement due to the possibility of standing water when a stream dries. Each sensor was placed downstream of the metal rod, and tubes were cleaned of any sediment on each visit.

\section{Stream network}

A total of 30 tributary streams in upper Val Roseg catchment were monitored for flow intermittency, temperature, and origin using the sensors (see Supporting Information Fig. S1). These tributaries represented essentially all streams comprising the fluvial network in the upper valley. In general, the east side of the catchment had fewer tributaries than the west side, and only one stream was found on the east side of the lake. Water sensors logged relative conductivity (unit = Lux, as modified from the light sensor) and temperature $\left({ }^{\circ} \mathrm{C}\right)$ on an hourly basis. Water sensors were installed in the streams on 03 July 2017, downloaded and removed from the field on 21 November 2017, reinstalled on 02 December with fresh batteries, and downloaded again on 06 June 2018 when all streams were accessible and snow free, essentially providing 11 months of continuous data. A HOBO BASE-U-1 pendant coupler was used to download data into HOBOware software, and missing data (generated when sensors logged while being downloaded) were estimated as the average of values observed $1 \mathrm{~h}$ prior to sensor collection and $1 \mathrm{~h}$ following redeployment.

\section{Water chemistry}

In addition to continuous measures by loggers, surface water in each stream was sampled three times over the study period: in July 2017, September 2017, and June 2018. Water samples were analyzed for silicate content $\left(\mathrm{mg} \mathrm{H}_{4} \mathrm{SiO}_{4} \mathrm{~L}^{-1}\right), \mathrm{pH}$, alkalinity $\left(\mathrm{mmol} \mathrm{L} \mathrm{L}^{-1}\right)$, nitrate $\left(\mu \mathrm{g} \mathrm{N} \mathrm{L}^{-1}\right)$, dissolved organic carbon (DOC; $\mathrm{mg} \mathrm{L}^{-1}$ ), total organic carbon (TOC; $\mathrm{mg} \mathrm{L}^{-1}$ ), orthophosphate $\left(\mu \mathrm{g} \mathrm{L}^{-1}\right)$, and total phosphorus $\left(\mu \mathrm{g} \mathrm{L}^{-1}\right)$ (after Tockner et al. 1997). A Titrando from Metrohm (Metrohm AG, Herisau, Switzerland) was used to measure alkalinity and $\mathrm{pH}$. A Shimadzu TOC-5000 (A) organic carbon analyzer (Shimadzu, Kyoto, Japan) was used to determine TOC and DOC. A Metrohm Ion Chromatograph was used measure nitrate and sulfate. Alkalinity, $\mathrm{pH}$, and silicate content were used in analyses to assess the chemical similarity among streams.

\section{Data analysis}

Eighteen metrics were calculated to express differences among streams according to four general categories, including the flow regime, temperature regime, water origin, and water chemistry (Supporting Information Table S1). We used individual principal component analysis (PCA) on mean-centered data to statistically show the gradient among streams for each of these four categories. Metrics were based on expert opinion and previous approaches to analyze intermittent flow regimes (Costigan et al. 2017). We included a maximum of six metrics within each PCA, and these were selected on the basis of ecological relevance and to minimize redundancy among included variables. Water origin was inferred from the measure of relative conductivity, with high relative conductivity representative of groundwater fed streams and progressively lower relative conductivity for glacier feed streams, snow-melt fed streams, and rain-fed streams (after Malard et al. 2000). Temperature conditions during nonflowing and freezing periods were assumed to be representative of the stream conditions and not removed before analysis. Individual PCAs of mean-centered data were performed on metrics to statistically show the gradient among streams in each category (Vaughan and Ormerod 2005). Site scores along PCA axis- 1 were used to best explain the gradient among study streams in each category. Following the PCA, Euclidean distances between sites were calculated and 
sites classified with a Ward clustering method that grouped sites with similar characteristics in each category. Ward clustering was selected due to its ability to produce groups of sites that minimize within-group dispersion, and its ability to cope with multivariate Euclidean space such as PCA. Permutational multivariate analysis of variance was performed to test clustering significance. The package "ade4" in $\mathrm{R}$ was used for all analyses (Chessel et al. 2004; R Core Team 2017), except permutational multivariate analysis of variance where the adonis function in vegan package was used (Oksanen et al. 2018).

Correlations between the response variable (i.e., flow intermittency) and explicative variables of temperature, chemistry, and origin were tested using generalized additive models (GAMs) (Wood 2006) and the PCA axis-1 scores for all variables. A GAM was chosen instead of other regression procedures because of its ability to handle nonlinear relationships between the response variable and the set of explanatory variables (Guisan et al. 2002). We used the fitted values of the GAM to plot the relationships between explanatory and response variables of each model. Selection of explanatory variables was done in a backward selection using $p$ values. GAMs were calculated with the GAM function from "mgcv" package in R (Wood 2006; R Core Team 2017). Prior to statistical analyses, heatmaps were plotted for exploratory analyses using the "plot3D" package in R. The degree of flow intermittency of streams determined by the PCA results was plotted on an aerial photo using ARCGIS software (ARCGIS 10.5, 2016, ESRI).

\section{Results}

\section{Water sensor performance}

Relative conductivity measured by the water sensors was related positively to spot-measured EC in the field $\left(R^{2}=0.78\right.$, $p<0.01$, Fig. 1a). Six measurements from the water sensors were substantially lower than predicted from the linear model between relative conductivity and EC (Fig. 1a). A strong positive relationship was found between water sensor temperature values and spot-measured values in the field $\left(R^{2}=0.97\right.$, $p<0.001$, Fig. 1b). When data were transformed to presence/absence of water (i.e., positive values meaning surface flow and zero values meaning no flow), water sensor data correlated strongly with field observations with only one false positive (Type I error) and no false negatives (Type II error) (Fig. 1c). The one false positive was due to a logger being buried under $50 \mathrm{~cm}$ of sediment and thus recorded hyporheic flow while the river bed was dry at the surface (Fig. 1c).

\section{Spatial and seasonal variation in flow intermittency}

Seven of the 30 measured streams dried periodically throughout the study period, 24 streams (80\%) went dry only during winter, and six streams had permanent surface flow (Fig. 2, Supporting Information Fig. S3). A high relative conductivity (Lux values) was observed for some streams during the study, permanent streams in particular. The starting point of the dry period ranged from early fall for six streams showing several episodic dry periods followed by rewetted periods (Fig. 2, left side of the heatmap) to later in fall for most of the drying streams (Fig. 2). All dry streams started to flow at the same time the following spring (April 2018, Fig. 2). Temperature was highest in all streams at the beginning of the study in July, then decreased in all streams to $0-5^{\circ} \mathrm{C}$ during the winter before increasing again in spring (Supporting Information Fig. S3).

\section{Ordination and classification of streams}

The four performed PCAs resulted in significantly different groups of streams. For each PCA, the two first axes expressed more than $50 \%$ of the total explained variation, with a maximum explained variation of $81 \%$ for the first axis based on (a)

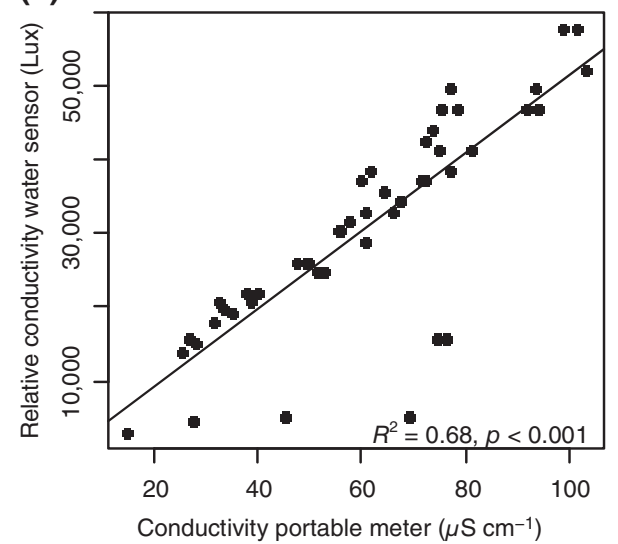

(b)

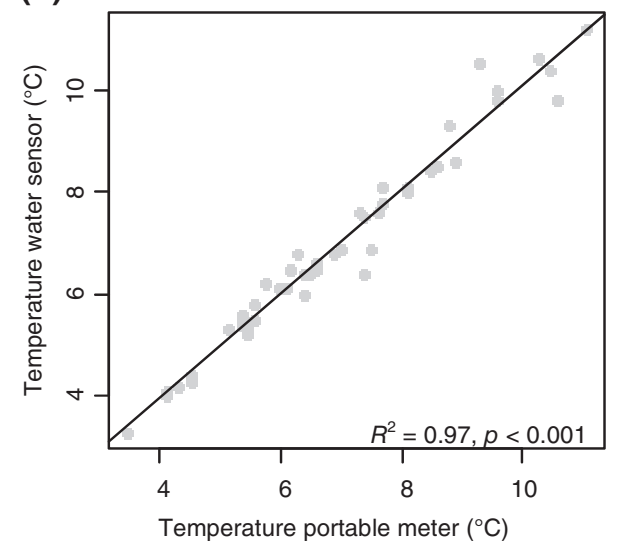

(c)

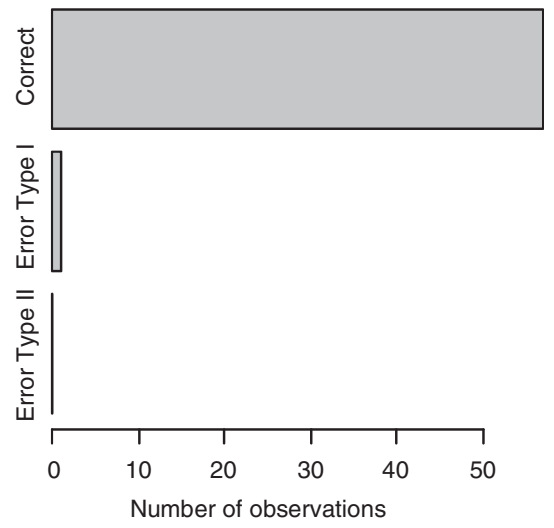

Fig. 1. Measure of sensor performance. Water sensor measures of relative conductivity (Lux) compared to $\mathrm{EC}\left(\mu \mathrm{S} \mathrm{cm}{ }^{-1}\right.$ at $\left.20^{\circ} \mathrm{C}\right)$ measures using a portable meter in the field (a). Linear regression showing the correlation between water temperature $\left({ }^{\circ} \mathrm{C}\right)$ measured by the sensors with water temperature measured by portable meters in the field (b). Histogram showing the concordance between measured and field observed presence of water in the study streams (shown are correct observations, Type I and Type II errors) (c). 


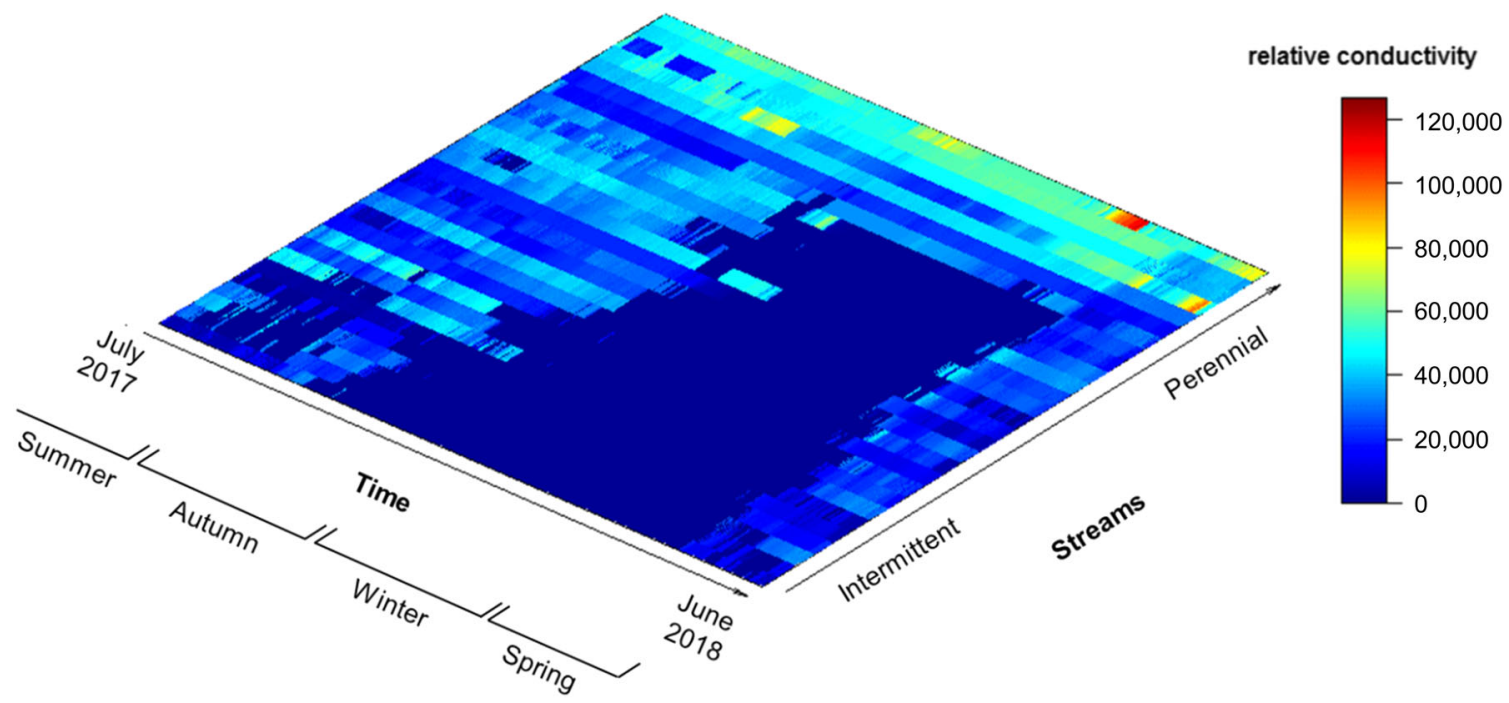

Fig. 2. Heatmap showing flow intermittency based on relative conductivity (colored scale in Lux) measured by water sensors from July 2017 to June 2018 for the 30 streams in the Val Roseg. A relative conductivity of 0 represents dry events during the study period.

water origin (Supporting Information Table S2). The PCA based on flow intermittency and its classification highlighted three groups of streams; that is, periodically intermittent, seasonally intermittent, and permanent streams (Fig. 3a, Supporting Information Figs. S4a, S5a; $F_{1.0}=6.1, p<0.001$ ) with a longer period of flow intermittence and early start of drying periods for periodically intermittent streams. Periodically intermittent streams showed episodes of dryness followed by rewetted periods, while seasonally intermittent streams typically went dry once at the end of the year. Periodically intermittent streams also went dry at the end of the year.

The PCA based on temperature separated streams in three groups along a gradient of warm to cold water (Fig. 3b, Supporting Information Figs. S4b, S5b; $F_{1.0}=7.5, p=0.002$ ) with maximum and minimum temperature contributing to most of the differentiation between groups. The PCA based on water origin separated streams into three groups along a gradient of high to low relative conductivity (Fig. 3c, Supporting Information Figs. S4c, S5c; $\left.F_{1.0}=47.7, p<0.001\right)$. Last, the PCA based on water chemistry separated three groups of streams along a gradient of low to high alkalinity (Fig. 3d, Supporting Information Figs. S4d, S5d; $\left.F_{1.0}=19.3, p<0.001\right)$ with silicate having a small effect on this differentiation.

\section{Modeling flow intermittency based on temperature and water origin}

The best model predicted flow intermittency based on average temperature and water origin (Fig. 4). There was a strong
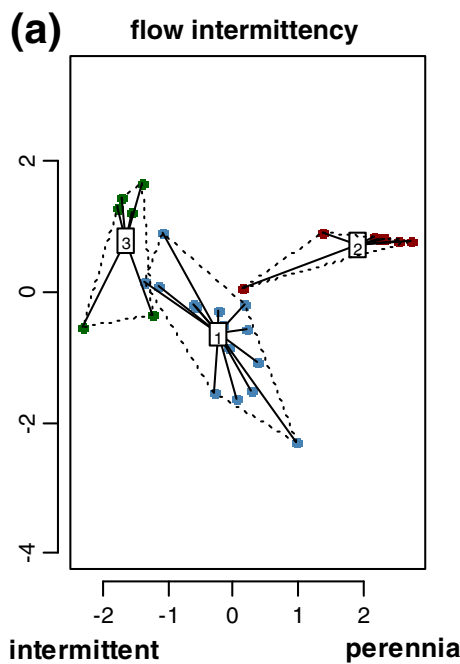

(b)

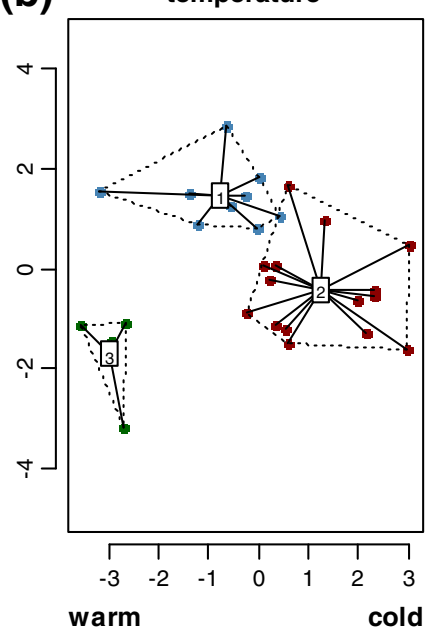

(c)

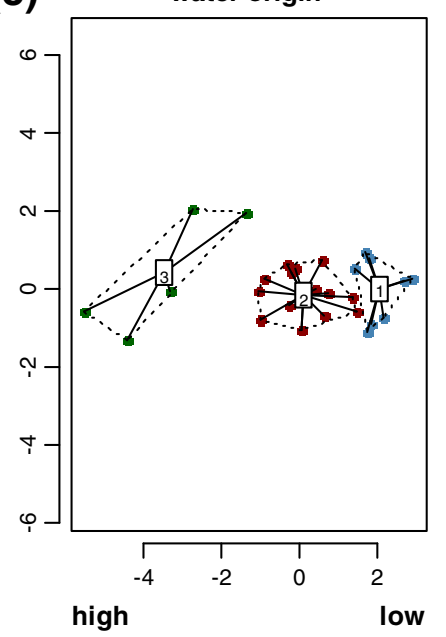

(d)

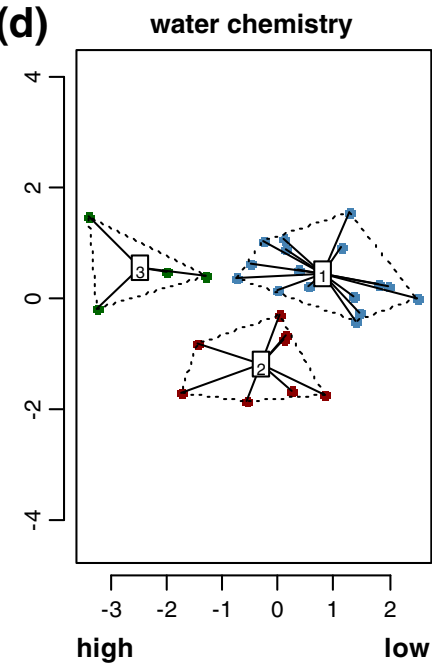

Fig. 3. PCA ordinations and classifications of streams based on flow intermittency (a), temperature (b), water origin (c), and water chemistry (d). 

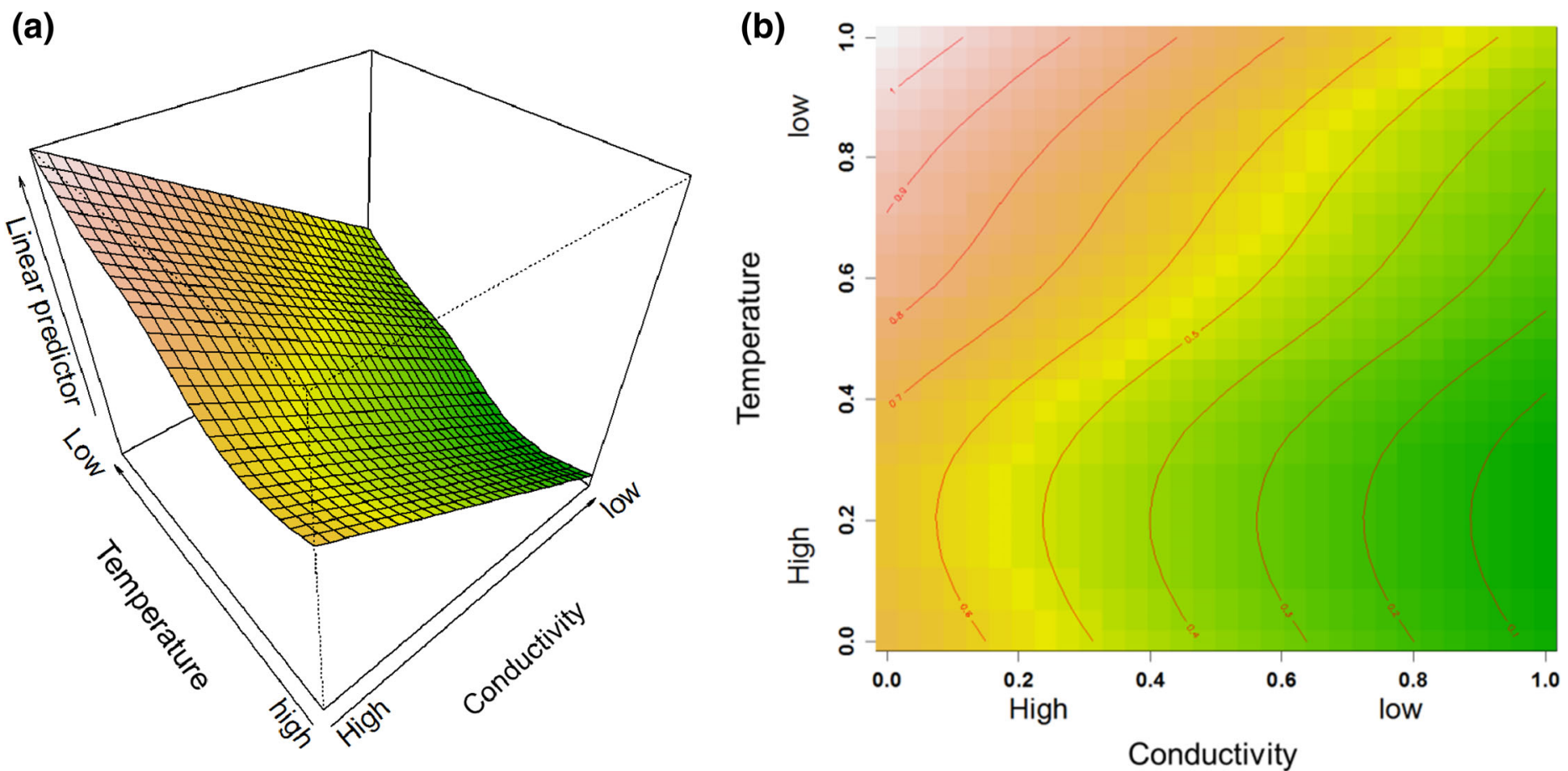

Fig. 4. A three-dimensional plot (a) showing stream representation based on GAM results integrating temperature and relative conductivity data to explain flow intermittency of streams in Val Roseg. Linear predictor represents expected response of flow intermittency. Red color represents more permanently flowing streams while yellow and green represent streams with high levels of flow intermittency. Plot (b) represents contour plot view of GAM model prediction.

correlation between flow intermittency and temperature (Supporting Information Fig. S6a; $F_{3.4}=8.6, p<0.001$ ) with streams having higher average temperature more likely to dry. Flow intermittency also was correlated with water origin (Supporting Information Fig. S6b; $F_{1.0}=48.3, p<0.001$ ) with streams having low relative conductivity more likely to dry (Fig. 4). Water origin (based on measures of relative conductivity) was positively related to chemical measures of alkalinity and silicate (Supporting Information Fig. S7; $p<10^{-6}$ and $p<0.001$, respectively).

\section{Mapping flow intermittency in the Val Roseg}

Based on the PCA results and its clustering, each stream was assigned to a class of flow intermittency and plotted on a geographical map (Fig. 5a). Permanent streams were mostly situated in the active floodplain (Fig. 5a) and had higher EC (mean $73.3 \mu \mathrm{S} \mathrm{cm}^{-1}$ ) and silicate concentrations (mean $\left.9.5 \mathrm{mg} \mathrm{L}^{-1}\right)$ compared to seasonally $\left(47.1 \mu \mathrm{S} \mathrm{cm}^{-1} ; 5.0 \mathrm{mg} \mathrm{L}^{-1}\right)$ and periodically $\left(43.5 \mu \mathrm{S} \mathrm{cm}^{-1} ; 6.4 \mathrm{mg} \mathrm{L}^{-1}\right)$ intermittent streams (Fig. 5b,c). Periodically intermittent streams were most commonly located along valley side slopes in the lower part of the catchment (Fig. 5a), and had higher temperature variability (coefficient of variation $[\mathrm{CV}]=142 \%$ ) than seasonally intermittent $(\mathrm{CV}=104 \%)$ and permanent $(\mathrm{CV}=64 \%)$ streams (Fig. $5 \mathrm{~d}$ ), as well as higher average temperature (mean $4.2^{\circ} \mathrm{C}$ ) than seasonally intermittent $\left(3.3^{\circ} \mathrm{C}\right)$ streams (Fig. 5e).

\section{Discussion}

In this study, we used water sensors modified from light sensors to measure the intermittency of streams in an alpine fluvial network at high temporal and spatial resolution. The results obtained from the high-resolution data showed that $80 \%$ (in number) of the streams in the Val Roseg catchment dried during the study year.

\section{ER sensor performance}

The ER sensors clearly indicated wet and dry periods in surface channels that were largely validated by field observations. An exception was a false positive where burial of the logger measured hyporheic saturation rather than the absence of surface water. A false negative also can occur where spatial heterogeneity in drying within the channel results in a "dry" signal while surface flow is still present upstream. We made two observations where spatial heterogeneity occurred in surface flow cessation, specifically flow cessation a short distance $(\sim 20 \mathrm{~m})$ upstream to where loggers were installed. These two observations were not considered false negatives as water was absent from the position of the installed logger and also absent downstream of the loggers. These examples highlight the importance of site selection when installing ER sensors (e.g., Adams et al. 2006). In the Val Roseg, headwater streams are narrow $(\sim 1-3 \mathrm{~m}$ wide) and relatively high gradient (median of $\sim 13^{\circ}$ slope across our sites) with limited subsurface 


\section{(a)}
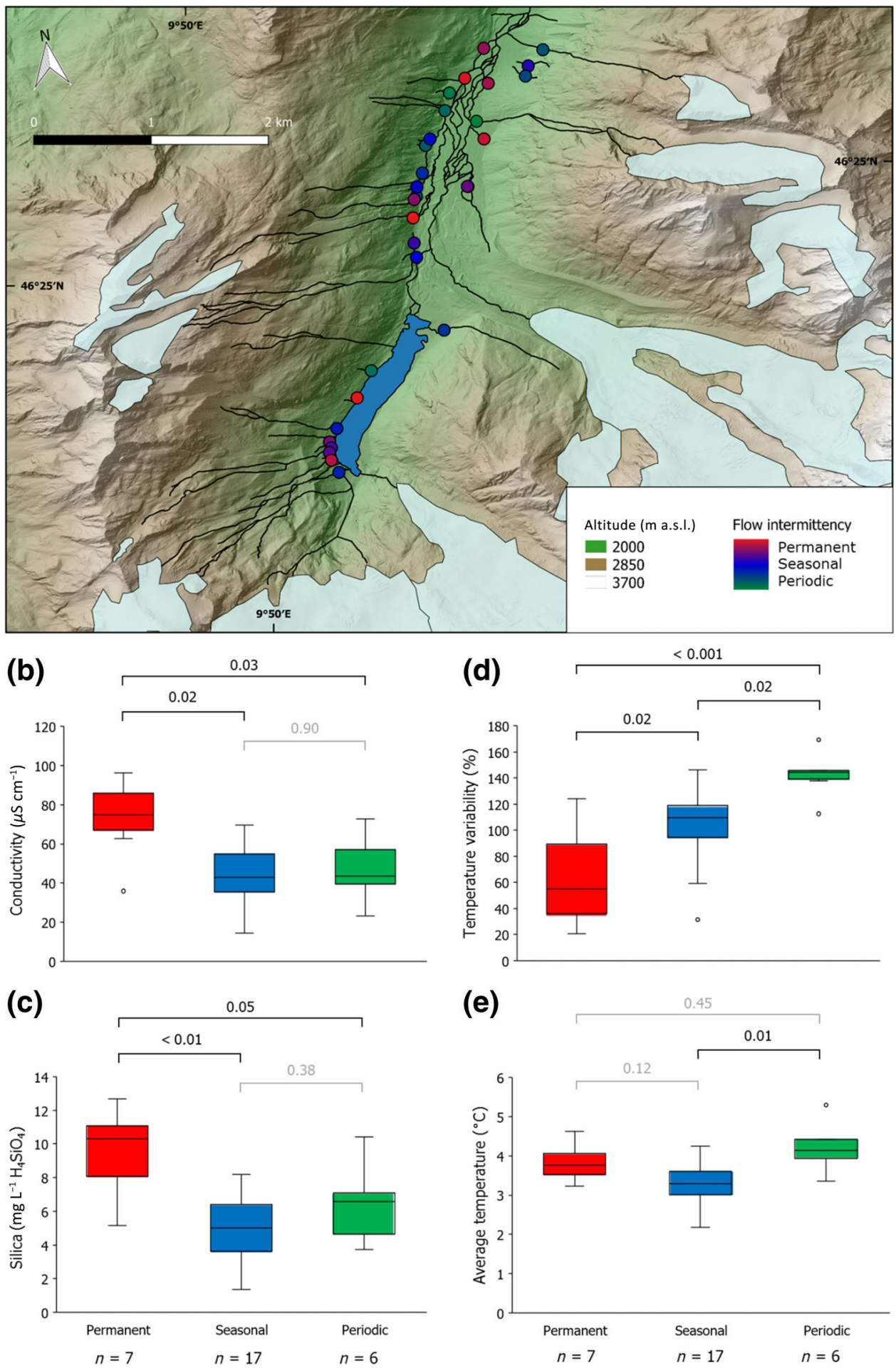

Fig. 5. (a) Map of Val Roseg with study streams depicted in color with respect to flow categories. Sites are colored with respect to flow permanence based on detection of water by in situ water sensors: permanent flow (red), seasonal/winter drying (blue), and periodic/year-round drying (green). Glacier extent as of 2017 is indicated by light blue fill. Box plots represent the three groups of streams and their respective average values of electric conductivity (b), silicate concentration (c), temperature variability $(\mathrm{CV})(\mathbf{d})$, and average temperature (e). $p$ values indicate results of Tukey's tests between hydrological groups, with nonsignificant $(p>0.05)$ results indicated by gray coloration. 
storage (Malard et al. 2000; Robinson and Matthaei 2007), and thus usually limited to single rather than multiple channels accompanied by pools or backwaters. In this respect, we are confident that ER sensors installed at a single location within the channel recorded the majority of stream flow periods.

The application of ER sensors could be more complicated under other geomorphological conditions such as from multiple channel situations. Furthermore, surface flow cessation can often result in partial drying of channels, such as into a disconnected series of variably persistent pools along main drainage lines (e.g., Bunn et al. 2006; Vazquez et al. 2011; Siebers et al. 2016). By installing loggers outside of existing pools along streams, we avoided measuring presence of water when a channel was not flowing. In highly braided systems or those with dynamic, rapidly changing beds, identification of "main" channels where surface flow can be expected to be most persistent may be difficult (e.g., Doering et al. 2007; Larned et al. 2011). As in our case, sensors also can be buried by shifting bed loads, necessitating careful consideration of whether hyporheic saturation correlates with surface flow (Blasch et al. 2002; Jaeger and Olden 2012). In the above situations, spatial heterogeneity in flow cessation and the presence of surface water within reaches would need to be investigated in greater detail (Peirce and Lindsay 2014).

Last, the magnitude and frequency of floods or spates is of vital ecological importance for many IRES (Bunn et al. 2006). ER sensors only record presence or absence of water, and thus would need to be complemented with flow measurements to assess discharge as well (Bhamjee et al. 2016). Notably, it may be advantageous to install additional ER sensors below the sediment to record hyporheic saturation (Blasch et al. 2002), especially in IRES where groundwater connectivity has a strong influence on surface-water persistence, ecological processes, and biodiversity (Goulsbra et al. 2014; Siebers et al. 2016). Frequent drying events could reflect water loss in streambed sediments and insufficient recharge of water. This mechanism could underline the measure of water presence in the sediment and its relationship with flow intermittency at the surface. Moreover, groundwater is an important refuge for aquatic biodiversity and an accurate assessment of groundwater presence could help identify mechanisms of biological resilience of drying streams.

\section{Modeling flow intermittency}

Flow intermittency was predicted best according to temperature and EC. The best model indicated that streams with low average temperature (average maximum $=11.5^{\circ} \mathrm{C}$ ) would more likely be permanent, while streams with higher temperature (average maximum $=19.0^{\circ} \mathrm{C}$ ) would more likely dry. Part of this correlation might be due to higher air than water temperatures in summer (i.e., dry streams have higher temperatures). This relationship thus likely also concurs with the influence of glaciers on temperature and their contribution to the release of water in alpine catchments. Streams fed by melting glaciers have low water temperature and are more likely to dry later in the season (i.e., winter) when the contribution of glaciers to surface flow is minimum or null due to freezing (Malard et al. 1999). The predominance of seasonally intermittent sites in the upper catchment, together with their relatively low temperature, suggests a glacial water source. These results are in contrast with Robinson et al. (2016), who suggested that glacial streams were the most intermittent within the Roseg fluvial network. Their study only encompassed the spring and summer months (May-August), whereas we observed that the greatest differences in flow intermittency between sites were driven by the timing and frequency of drying events in autumn (September-October). We suggest that streams fed mostly by rainfall with no direct connection to glaciers have higher average temperature and are more likely to dry periodically (Malard et al. 2006).

In this study, streams with high EC $\left(\mathrm{ca}>65 \mu \mathrm{S} \mathrm{cm}^{-1}\right)$ and silicate concentrations (ca $>8 \mathrm{mg} \mathrm{L}^{-1} \mathrm{H}_{4} \mathrm{SiO}_{4}$ ) were more likely to have permanent flow. In Val Roseg, these measurements are most representative of streams where shallow alluvial groundwater is the major water source (Malard et al. 1999, 2006). While glacial meltwater often infiltrates and travels through the ground before discharging into stream channels, it typically has lower silicate concentrations than alluvial groundwater due to less weathered substrates and shorter flowpaths (Malard et al. 1999, 2006; Anderson 2005). Consequently, silicate concentrations and specific conductivity tend to decrease from groundwater-fed streams through predominantly glacier-fed (including both englacial and subglacial flowpaths) and then largely overland flow-driven channels (Malard et al. 1999, 2006; Tockner et al. 2002; Brown et al. 2003). Our results suggest that groundwater upwellings provide a consistent, year-round water source to streams, and that the degree of groundwater connectivity thus determines whether streams in Val Roseg maintain perennial flow.

Flow intermittency in Val Roseg might thus be correlated with the definitions of alpine streams proposed by Ward (1994) and later modified by Brown et al. (2003) based on water origin. Rhithral streams, with snowmelt-dominated flow regimes, typically have the widest range in temperatures among alpine stream types (Tockner et al. 1997) and the lowest ionic concentrations (cf. nitrate; Tockner et al. 1997). Kryal streams, with large contributions of glacial meltwater, can exhibit very low temperatures, although with significant fluctuations due to diel cycles of solar radiation and glacial melt (Malard et al. 2006). Krenal streams, largely fed by groundwater, have greater ionic enrichment and specific conductance than the other types (Brown et al. 2003) as well as more stable temperature regimes (Tockner et al. 1997). Water origin has a fundamental influence on benthic communities of alpine streams through channel stability and water temperature (Ward 1994; Brown et al. 2003). As flow intermittency also correlates strongly with water origin, it thus represents an additional source of environmental variability which may 
contribute to, or amplify, the effects of water origin on alpine stream ecosystems.

Based on model results, we infer that groundwater-fed streams are the most permanent streams followed by streams fed by glaciers. Glaciers provide water during spring and summer when air temperature is high and snow packs are gone. Snow packs contribute to the water release in the entire catchment during winter and spring, but are usually absent during summer and fall. Based on the model relating flow intermittency to temperature and conductivity, the four main sources of water in the Val Roseg can be ordinated from groundwaterfed streams to rainfall-fed streams (Fig. 6). The plot shows that groundwater-fed streams are permanent, while glaciers contribute to surface flows when streams lack major groundwater inputs. Last, snowmelt is seasonal (predominantly spring) and less permanent, while rainfall is more periodic in contributing to surface flows. Our results thus imply that: (1) flow intermittency in alpine catchments might be inferred from relative conductivity data, silicate concentrations, or temperature regimes, but (2) studies showing strong effects of water origin or temperature on alpine stream communities (e.g., Khamis et al. 2016) may also have been influenced by the ecological effects of flow intermittency. We suggest that further investigations of the effects of water source on alpine benthic communities should also strongly consider measuring flow intermittency as an additional, potentially significant driver of ecosystem structure.

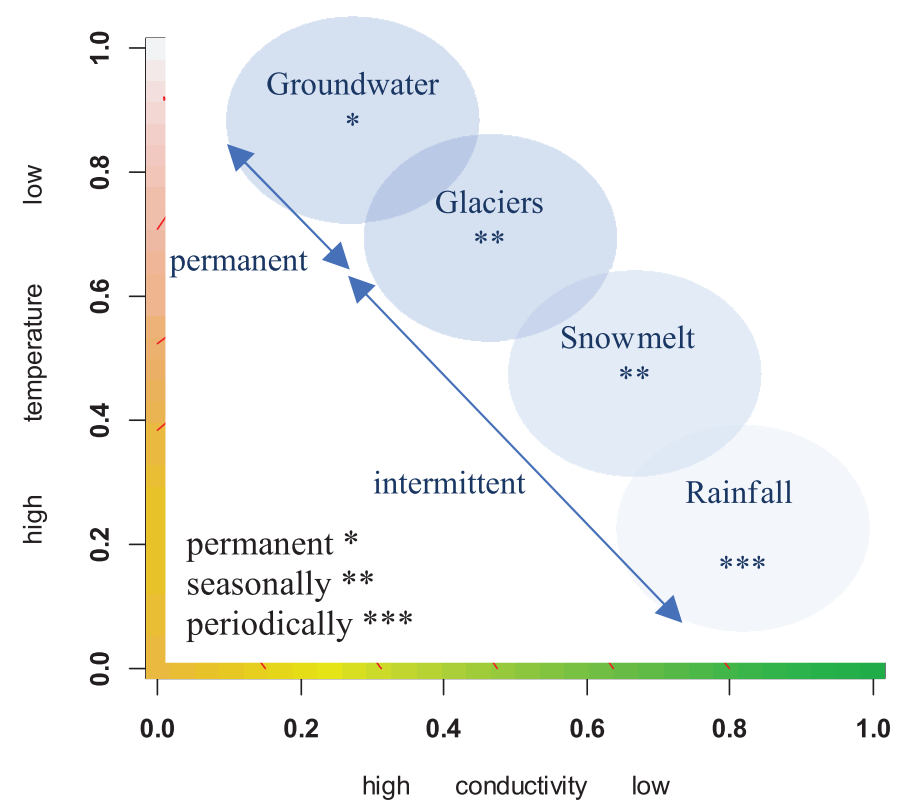

Fig. 6. Hypothetical representation of the four main sources of water in the Val Roseg. The four sources are plotted on the resulting contour plot of GAM model prediction. Streams fed by groundwater represent the most permanent streams, followed by streams fed by glaciers, those fed by snowmelt and then those periodically fed by rainfall. The four sources are related to temperature and water origin highlighted as key parameters of the GAM model.

\section{Flow intermittency in mountains}

Some $80 \%$ of the headwater streams monitored in the Val Roseg catchment dried on a periodic or seasonal basis. In contrast to this network pattern, Sando and Blasch (2015) observed a lower proportion ( 33\%) of intermittency among headwater streams of a montane watershed in the northern Rocky Mountains, U.S.A., with intermittency most strongly correlated with lower snowpack persistence. Furthermore, Jaeger and Olden (2012) observed that headwaters were less intermittent than downstream reaches in a semiarid montane catchment due to an increased upstream incidence of springs, snowmelt, and monsoonal rainfall. Taken together, these studies highlight the difficulty in generalizing drivers of headwater intermittency across catchments with diverse climates. In both cases, however, perennial streamflow also was associated with less permeable underlying geology (Jaeger and Olden 2012; Sando and Blasch 2015). Furthermore, Goulsbra et al. (2014) observed complex spatial patterns of intermittency in a highly incised peatland catchment, with precipitation-induced flow dependent on water table depths in addition to drainage density.

In the Val Roseg, headwater intermittency is likely driven by complex interactions between climate, precipitation, water source, and geology, rather than any single factor (Malard et al. 2000; Robinson and Matthaei 2007; Robinson et al. 2016). Flow intermittency occurs naturally in alpine environments. However, current climate models predict temporal shifts in precipitation within European alpine areas along with increases in temperature, with significant increases in the intermittency and drying of alpine waters (Horton et al. 2006; Zemp et al. 2006; IPCC 2014). Consequently, streams currently influenced by glacier melt are likely to enhance network contraction in the future, thereby increasing the duration and frequency of flow cessation and its concomitant effects on biodiversity and ecosystem function (Milner et al. 2009; Slemmons et al. 2013; Cauvy-Fraunie et al. 2015). The approach we describe here may provide a tool for documenting such changes and understanding their ecological consequences.

\section{References}

Adams, E. A., S. A. Monroe, A. E. Springer, K. W. Blasch, and D. J. Bills. 2006. Electrical resistance sensors record spring flow timing, Grand Canyon, Arizona. Ground Water 44: 630-641. doi:10.1111/j.1745-6584.2006.00223.x

Alexander, R. B., E. W. Boyer, R. A. Smith, G. E. Schwarz, and R. B. Moore. 2007. The role of headwater streams in downstream water quality. J. Am. Water Resour. Assoc. 43: 41-59. doi:10.1111/j.1752-1688.2007.00005.x

Anderson, S. P. 2005. Glaciers show direct linkage between erosion rate and chemical weathering fluxes. Geomorphology 67: 147-157. doi:10.1016/j.geomorph.2004.07.010

Bhamjee, R., J. B. Lindsay, and J. Cockburn. 2016. Monitoring ephemeral headwater streams: A paired-sensor approach. Hydrol. Process. 30: 888-898. doi:10.1002/hyp.10677 
Bishop, K., I. Buffam, M. Erlandsson, J. Fölster, H. Laudon, J. Seibert, and J. Temnerud. 2008. Aqua incognita: The unknown headwaters. Hydrol. Process. 22: 1239-1242. doi: 10.1002/hyp.7049

Blasch, K. W., T. P. A. Ferré, A. H. Christensen, and J. P. Hoffmann. 2002. New field method to determine streamflow timing using electrical resistance sensors. Vadose Zone J. 1: 289-299. doi:10.2136/vzj2002.2890

Brown, L. E., D. M. Hannah, and A. M. Milner. 2003. Alpine stream habitat classification: An alternative approach incorporating the role of dynamic water source contributions. Arct. Antarct. Alp. Res. 35: 313-322. doi:10.1657/15230430(2003)035[0313:ASHCAA]2.0.CO;2

Brown, L. E., and others. 2017. Functional diversity and community assembly of river invertebrates show globally consistent responses to decreasing glacier cover. Nat. Ecol. Evol. 2: 325-333.

Bunn, S. E., M. C. Thoms, S. K. Hamilton, and S. J. Capon. 2006. Flow variability in dryland rivers: Boom, bust and the bits in between. River Res. Appl. 22: 179-186. doi:10.1002/ rra.904

Burgherr, P., and J. V. Ward. 2001. Longitudinal and seasonal distribution patterns of the benthic fauna of an alpine glacial stream (Val Roseg, Swiss Alps). Freshw. Biol. 46: 1705-1721. doi:10.1046/j.1365-2427.2001.00853.x

Cauvy-Fraunie, S., R. Espinosa, P. Andino, D. Jacobsen, and O. Dangles. 2015. Invertebrate metacommunity structure and dynamics in an Andean glacial stream network facing climate change. PLoS One 10: e0136793. doi:10.1371/ journal.pone.0136793

Chapin, T. P., A. S. Todd, and M. P. Zeigler. 2014. Robust, lowcost data loggers for stream temperature, flow intermittency, and relative conductivity monitoring. Water Resour. Res. 50: 6542-6548. doi:10.1002/2013WR015158

Chessel, D., A. B. Dufour, and J. Thioulouse. 2004. The ade 4 package-I: One-table methods. R News 4: 5-10.

Cid, N., and others. 2016. A biological tool to assess flow connectivity in reference temporary streams from the Mediterranean Basin. Sci. Total Environ. 540: 178-190.

Constantz, J., D. Stonestorm, A. E. Stewart, R. Niswonger, and T. R. Smith. 2001. Analysis of streambed temperatures in ephemeral channels to determine streamflow frequency and duration. Water Resour. Res. 37: 317-328. doi:10.1029/ 2000WR900271

Costigan, K., C. Leigh, E. Sauquet, M. Kennard, T. Datry, and A. J. Boulton. 2017. Flow regimes in intermittent rivers and ephemeral streams, p. 51-78. In T. Datry, N. Bonada, and A. J. Boulton [eds.], Intermittent rivers and ephemeral streams: Ecology and management. Elsevier.

Datry, T., S. T. Larned, and K. Tockner. 2014. Intermittent rivers: A challenge for freshwater ecology. Bioscience 64: 299-235.

Datry, T., N. Bonada, and A. J. Boulton. 2017. General introduction, p. 1-20. In T. Datry, N. Bonada, and A. J. Boulton [eds.],
Intermittent rivers and ephemeral streams: Ecology and management. Elsevier.

Doering, M., U. Uehlinger, A. Rotach, D. R. Schlaepfer, and K. Tockner. 2007. Ecosystem expansion and contraction dynamics along a large Alpine alluvial corridor (Tagliamento River, Northeast Italy). Earth Surf. Process. Landf. 32: 1693-1704. doi:10.1002/esp.1594

Fritz, K. M., and others. 2013. Comparing the extent and permanence of headwater streams from two field surveys to values from hydrographic databases and maps. J. Am. Water Resour. Assoc. 49: 867-882. doi:10.1111/jawr.12040

Gallart, F., P. Llorensa, J. Latrona, N. Cid, M. Rieradevall, and N. Prat. 2016. Validating alternative methodologies to estimate the regime of temporary rivers when flow data are unavailable. Sci. Total Environ. 565: 1001-1010.

Gomi, T., R. C. Sidle, and J. S. Richardson. 2002. Understanding processes and downstream linkages of headwater systems. Bioscience 52: 905-916. doi:10.1641/0006-3568 (2002)052[0905:UPADLO]2.0.CO;2

González-Ferreras, A. M., and J. Barquín. 2017. Mapping the temporary and perennial character of whole river networks. Water Resour. Res. 53: 6709-6724. doi:10.1002/ 2017WR020390

Goulsbra, C., M. Evans, and J. Lindsay. 2014. Temporary streams in a peatland catchment: Pattern, timing, and controls on stream network expansion and contraction. Earth Surf. Process. Landf. 39: 790-803. doi:10.1002/esp. 3533

Guisan, A., T. C. Edwards, and T. Hastie. 2002. Generalized linear and generalized additive models in studies of species distributions: Setting the scene. Ecol. Model. 157: 89-100. doi:10.1016/S0304-3800(02)00204-1

Horton, P., B. Schaefli, A. Mezghani, B. Hingray, and A. Musy. 2006. Assessment of climate-change impacts on alpine discharge regimes with climate model uncertainty. Hydrol. Process. 20: 2091-2109. doi:10.1002/hyp.6197

IPCC. 2014. Climate change 2014: Synthesis report. Cambridge Univ. Press.

Jaeger, K. L., and J. D. Olden. 2012. Electrical resistance sensor arrays as a means to quantify longitudinal connectivity of rivers. River Res. Appl. 28: 1843-1852. doi:10.1002/rra.1554

Khamis, K., L. E. Brown, D. M. Hannah, and A. M. Milner. 2016. Glacier-groundwater stress gradients control alpine river biodiversity. Ecohydrology 9: 1263-1275. doi:10. 1002/eco.1724

Larned, S. T., J. Schmidt, T. Datry, C. P. Konrad, J. K. Dumas, and J. C. Diettrich. 2011. Longitudinal river ecohydrology: Flow variation down the lengths of alluvial rivers. Ecohydrology 4: 532-548. doi:10.1002/eco.126

Leigh, C., A. J. Boulton, J. L. Courtwright, K. Fritz, C. L. May, R. H. Walker, and T. Datry. 2016. Ecological research and management of intermittent rivers: An historical review and future directions. Freshw. Biol. 61: 1181-1199. doi:10. 1111/fwb.12646 
Leigh, C., and T. Datry. 2017. Drying as a primary hydrological determinant of biodiversity in river systems: A broadscale analysis. Ecography 40: 487-499. doi:10.1111/ecog. 02230

Malard, F., K. Tockner, and J. Ward. 1999. Shifting dominance of subcatchment water sources and flow paths in a glacial floodplain, Val Roseg, Switzerland. Arct. Antarct. Alp. Res. 31: $135-150$.

Malard, F., K. Tockner, and J. V. Ward. 2000. Physico-chemical heterogeneity in a glacial riverscape. Landsc. Ecol. 15: 679-695. doi:10.1023/A:1008147419478

Malard, F., U. Uehlinger, R. Zah, and K. Tockner. 2006. Floodpulse and riverscape dynamics in a braided glacial river. Ecology 87: 704-716. doi:10.1890/04-0889

Meyer, J. L., D. L. Strayer, J. B. Wallace, S. L. Eggert, G. S. Helfman, and N. E. Leonard. 2007. The contribution of headwater streams to biodiversity in river networks. J. Am. Water Resour. Assoc. 43: 86-103.

Milner, A. M., L. E. Brown, and D. M. Hannah. 2009. Hydroecological response of river systems to shrinking glaciers. Hydrol. Process. 23: 62-77. doi:10.1002/hyp.7197

Milner, A. M., and others. 2017. Glacier shrinkage driving global changes in downstream systems. Proc. Natl. Acad. Sci. USA 114: 9770-9778.

Oksanen, J., and others. 2018. Vegan: Community ecology package. R package version 2.5-1. [accessed 2018 February 01]. Available from https://CRAN.R-project.org/package= vegan

Oueslati, O., A. M. De Girolamo, A. Abouabdillah, T. R. Kjeldsen, and A. Lo Porto. 2015. Classifying the flow regimes of Mediterranean streams using multivariate analysis. Hydrol. Process. 29: 4666-4682. doi:10.1002/ hyp. 10530

Peirce, S. E., and J. B. Lindsay. 2014. Characterizing ephemeral streams in a southern Ontario watershed using electrical resistance sensors. Hydrol. Process. 29: 103-111.

Porter, J. H., E. Nagy, T. K. Kratz, P. Hanson, S. L. Collins, and P. Arzberger. 2009. New eyes on the world: Advanced sensors for ecology. Bioscience 59: 385-397. doi:10.1525/bio. 2009.59.5.6

R Core Team. 2017. R: A language and environment for statistical computing. R Foundation for Statistical Computing.

Robinson, C. T., and S. Matthaei. 2007. Hydrological heterogeneity of an Alpine stream/lake network in Switzerland. Hydrol. Process. 21: 3146-3154. doi:10.1002/hyp. 6536

Robinson, C. T., D. Tonolla, B. Imhof, R. Vukelic, and U. Uehlinger. 2016. Flow intermittency, physico-chemistry and function of headwater streams in an Alpine glacial catchment. Aquat. Sci. 78: 327-341. doi:10.1007/s00027015-0434-3

Rode, M., and others. 2016. Sensors in the stream: The highfrequency wave of the present. Environ. Sci. Technol. 50: 10297-10307. doi:10.1021/acs.est.6b02155
Sando, R., and K. W. Blasch. 2015. Predicting alpine headwater stream intermittency: A case study in the northern Rocky Mountains. Ecohydrol. Hydrobiol. 15: 68-80. doi:10. 1016/j.ecohyd.2015.04.002

Sertic, P. M., and C. T. Robinson. 2015. Spatio-temporal shifts of macroinvertebrate drift and benthos in headwaters of a retreating glacier. Hydrobiologia 751: 25-41.

Siebers, A. R., N. E. Pettit, G. Skrzypek, J. B. Fellman, S. Dogramaci, and P. F. Grierson. 2016. Alluvial ground water influences dissolved organic matter biogeochemistry of pools within intermittent dryland streams. Freshw. Biol. 61: 1228-1241. doi:10.1111/fwb.12656

Slemmons, K. E., J. E. Saros, and K. Simon. 2013. The influence of glacial meltwater on alpine aquatic ecosystems: A review. Environ. Sci. Process. Impacts 15: 1794-1806. doi: 10.1039/c3em00243h

Snelder, T. H., T. Datry, N. Lamouroux, S. T. Larned, E. Sauquet, H. Pella, and C. Catalogne. 2013. Regionalization of patterns of flow intermittence from gauging station records. Hydrol. Earth Syst. Sci. 17: 2685-2699. doi:10. 5194/hess-17-2685-2013

Spence, C., and S. Mengistu. 2016. Deployment of an unmanned aerial system to assist in mapping an intermittent stream. Hydrol. Process. 30: 493-500. doi:10. 1002/hyp.10597

Stubbington, R., and others. 2018. Biomonitoring of intermittent rivers and ephemeral streams in Europe: Current practice and priorities to enhance ecological status assessments. Sci. Total Environ. 618: 1096-1113.

Tockner, K., F. Malard, P. Burgherr, C. T. Robinson, U. Uehlinger, R. Zah, and J. V. Ward. 1997. Physico-chemical characterization of channel types in a glacial floodplain ecosystem (Val Roseg, Switzerland). Arch. Hydrobiol. 140: 433-463.

Tockner, K., F. Malard, U. Uehlinger, and J. V. Ward. 2002. Nutrients and organic matter in a glacial river-floodplain system (Val Roseg, Switzerland). Limnol. Oceanogr. 47: 266-277. doi:10.4319/lo.2002.47.1.0266

Uehlinger, U., F. Malard, and J. V. Ward. 2003. Thermal patterns in the surface waters of a glacial river corridor (Val Roseg, Switzerland). Freshw. Biol. 48: 284-300. doi:10. 1046/j.1365-2427.2003.01000.x

Vaughan, I. P., and S. J. Ormerod. 2005. Increasing the value of principal components analysis for simplifying ecological data: A case study with rivers and river birds. J. Appl. Ecol. 42: 487-497. doi:10.1111/j.1365-2664. 2005.01038.x

Vazquez, E., S. Amalfitano, S. Fazi, and A. Butturini. 2011. Dissolved organic matter composition in a fragmented Mediterranean fluvial system under severe drought conditions. Biogeochemistry 102: 59-72. doi:10.1007/s10533010-9421-X

Ward, J. V. 1994. Ecology of alpine streams. Freshw. Biol. 32: 277-294. doi:10.1111/j.1365-2427.1994.tb01126.x 
Wood, S. 2006. Generalized additive models: An introduction with R. Chapman and Hall/CRC.

Zemp, M., W. Haeberli, M. Hoelzle, and F. Paul. 2006. Alpine glaciers to disappear within decades? Geophys. Res. Lett. 33: L13504. doi:10.1029/2006GL026319

\section{Acknowledgments}

We thank the Aua chemical lab at Eawag for analysis of water samples; A. Raffainer for help in sensor development; C. Berner, D. Pellanda, and M. Frei for IT support; and C. Jolidon for lab support. We are grateful to Lucrezia and Wolfgang Pollak-Thom, and the staff of the Hotel Restaurant Roseg Gletscher, for their hospitality. The associate editor, Ryan Sponseller, and two anonymous reviewers further provided suggestions that greatly improved the quality of this article. This project was made possible by financial support from Eawag, Ernst Göhner Foundation, Gelbert Foundation, and the canton Graubünden.

\section{Conflict of Interest}

None declared.

Submitted 22 October 2018

Revised 30 March 2019

Accepted 16 July 2019

Associate editor: Ryan Sponseller 